\title{
INDICADORES MICROBIANOS DE QUALIDADE DO SOLO EM DIFERENTES SISTEMAS DE MANEJO(1)
}

\author{
Bruno Brito Lisboa ${ }^{(2)}$, Luciano Kayser $\operatorname{Vargas}^{(2)}$, Andressa \\ Oliveira da Silveira ${ }^{(3)}$, Adriana Ferreira Martins ${ }^{(2)}$ \& Pedro
}

Alberto Selbach(4)

\begin{abstract}
RESUMO
A atividade agrícola, mediante diferentes práticas de manejo, pode alterar a capacidade produtiva do solo. Assim, há necessidade de se avaliar o impacto de uma determinada prática sobre o solo. Este trabalho analisou diversos atributos microbianos para avaliar a qualidade do solo submetido a diferentes sistemas de preparo e de culturas, em relação a um sistema referência. Os atributos analisados foram a atividade das enzimas $\beta$-glicosidase, urease, fosfatase ácida e arilsulfatase, juntamente com a determinação da atividade respiratória e da biomassa da microbiota do solo. Os sistemas de manejo avaliados foram os preparos de solo direto (PD) e convencional (PC), e os sistemas de culturas foram duas rotações e pousio no inverno. Além desses sistemas, foi avaliado também o campo natural (CN) - este considerado como condição original do solo para a realização de comparações entre os diferentes manejos. As análises foram realizadas em quatro períodos distintos, ao longo de dois anos agrícolas. Os resultados, nas quatro avaliações, indicaram que a atividade das enzimas, assim como a biomassa e a respiração microbianas, foi menor no $\mathrm{PC}$ em relação aos demais sistemas, enquanto o CN e o PD tenderam a apresentar resultados semelhantes, indicando a capacidade do PD em manter a qualidade original do solo. Por sua vez, os sistemas de culturas avaliados não influenciaram significativamente os atributos avaliados.
\end{abstract}

Termos de indexação: biomassa microbiana, atividade microbiana, preparo de solo.

(1) Recebido para publicação em 3 setembro de 2009 e aprovado em 7 novembro de 2011.

(2) Pesquisador da Fundação Estadual de Pesquisa Agropecuária - FEPAGRO. Rua Gonçalves Dias 570, CEP 90130-060 Porto Alegre (RS). E-mail: bruno@fepagro.rs.gov.br

(3) Doutoranda em Ciência do Solo, Universidade Federal do Rio Grande do Sul - UFRGS. Av. Bento Gonçalves 7712, CEP 91540-000 Porto Alegre (RS). E-mail: aosilveira@hotmail.com

(4) Professor Adjunto do Departamento de Solos. UFRGS. E-mail: pedro.selbach@ufrgs.br 


\title{
SUMMARY: MICROBIAL INDICATORS OF SOIL QUALITY IN DIFFERENT MANAGEMENT SYSTEMS
}

\begin{abstract}
Agricultural activity, by the application of different soil management practices, can cause impacts on soil production capacity that need to be assessed. In this study, different microbiological parameters were evaluated, to assess the relation of soil quality with different tillage practices and crop systems, in comparison to a natural reference soil. The activities of $\beta$-glucosidase, urease, acid phosphatase and arylsulphatase were evaluated, as well as soil microbial respiratory activity and microbial biomass. Conventional tillage (CT) and no-tillage (NT) were evaluated in two crop rotations and winter fallow. In addition, natural pasture (NP) was also evaluated as reference, for comparison with the other management systems. The analyses were carried out in four growing seasons in two years. The results of the four seasons indicated that the enzyme activities, as well as microbial biomass and respiratory activity, were lower in CT than in the other systems, while results in NP and NT tended to be similar, indicating the capacity of NT to maintain the original soil quality. On the other hand, the evaluated parameters were in general not significantly influenced by the crop systems.
\end{abstract}

Index terms: microbial biomass, microbial activity, soil tillage.

\section{INTRODUÇÃO}

A manutenção da qualidade do solo, ou mesmo a sua melhoria, é fundamental para a sustentabilidade de agroecossistemas, visando à produção agrícola $\mathrm{e}$ à preservação ambiental (Doran \& Jones, 1996). O manejo adequado dos solos agrícolas é o principal fator a ser considerado quando se almeja a produção agrícola sustentável, uma vez que os sistemas de preparo e os sistemas de culturas interferem de modo significativo nas propriedades físicas, químicas e biológicas do solo (Carter, 1986; Cattelan \& Vidor, 1990; Govaerts et al., 2007), as quais compõem o tripé sobre o qual se assenta a qualidade do solo (Doran \& Jones, 1996).

Os sistemas de preparo de solo diferem, essencialmente, quanto ao grau de mobilização e à forma de disposição dos resíduos vegetais no solo. O preparo convencional tem como característica principal o revolvimento do solo por meio de operações de aração e gradagem, com a incorporação dos resíduos vegetais. Esse sistema apresenta problemas como a perda da qualidade estrutural do solo, redução dos teores de matéria orgânica, erosão superficial e compactação abaixo da camada arável. O sistema plantio direto surgiu como uma alternativa para reduzir esses processos de degradação, mediante a eliminação das operações de revolvimento do solo, o que proporciona a redução da erosão e o aumento dos teores de C orgânico do solo (Alvarez, 1995; Bayer \& Mielniczuk, 1997). Contudo, alguns problemas podem estar associados ao plantio direto, como a formação de uma camada superficial de solo compactado, capaz de reduzir o crescimento radicular das culturas (Collares et al., 2006).
Por sua vez, os sistemas de culturas podem influenciar o solo no que se refere à disponibilidade de nutrientes, profundidade de exploração radicular, quantidade e qualidade dos resíduos vegetais aportados. Com isso, alteram a atividade e diversidade microbiana (Balota et al., 2004), bem como as condições físicas (Albuquerque et al., 1995) e químicas (Bayer \& Mielniczuk, 1997) do solo.

Para inferir sobre o impacto de práticas de manejo sobre a qualidade do solo, recomenda-se a avaliação de indicadores físicos, químicos e biológicos do solo, levando-se em consideração, ainda, a complexidade de suas inter-relações (Doran \& Jones, 1996). A matéria orgânica (MO) do solo é um indicador que satisfaz essa condição, pois ela influencia, de forma direta, fatores como estabilidade de agregados, estrutura, infiltração e retenção de água, resistência à erosão, disponibilidade de nutrientes, atividade microbiana, capacidade de troca de cátions e emissão de gases para a atmosfera (Mielniczuk, 1999; Reeves, 1997). Entretanto, as alterações na matéria orgânica em decorrência das práticas de manejo podem ser identificadas somente anos após o emprego periódico destas, de maneira que, se a perturbação for pontual, dificilmente a MO poderá ser utilizada como um indicador dos impactos promovidos (Powlson \& Brookes, 1987).

Entre os indicadores de qualidade de solo alternativos à MO, os indicadores microbianos merecem especial atenção. Segundo Dick et al. (1996), as comunidades microbianas do solo são responsáveis por inúmeros processos e funções, como a decomposição de resíduos, ciclagem de nutrientes, síntese de substâncias húmicas, agregação e degradação de compostos xenobióticos. Indicadores 
bioquímicos, como atividade de enzimas, possuem elevado potencial para a avaliação da qualidade do solo em sistemas agrícolas, por apresentarem alta sensibilidade, permitindo avaliações logo após a ocorrência das perturbações no solo (Gil-Sotres et al., 2005). Também a biomassa microbiana é considerada um bom indicador de qualidade do solo. Carter (1986) observou que a análise do teor de $\mathrm{C}$ e de $\mathrm{N}$ na biomassa microbiana do solo foi mais sensível para identificar as modificações promovidas por operações de preparo do que avaliações dos teores de $\mathrm{C}$ e $\mathrm{N}$ total.

O objetivo do presente trabalho foi avaliar a qualidade do solo em diferentes sistemas de preparo de solo, em duas rotações de culturas ou em solo mantido sob pousio no inverno, comparando-os com um sistema referencial, por meio do emprego de indicadores microbianos.

\section{MATERIAL E MÉTODOS}

\section{Amostragens e tratamentos}

O experimento no qual foram coletadas as amostras para a realização deste trabalho caracteriza-se por ser de longa duração, tendo sido instalado no ano de 2000, em área de campo natural, sem histórico de cultivos anteriores, sobre solo classificado como Argissolo Vermelho distrófico típico (Embrapa, 2006). A área está localizada na Estação Experimental Agronômica da UFRGS, no município de Eldorado do Sul (RS), na região fisiográfica da

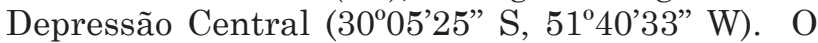
clima regional é classificado como subtropical de verão quente úmido do tipo fundamental $\mathrm{Cfa}$, conforme a classificação de Köppen.

As amostragens foram realizadas em quatro períodos, ao longo de dois anos agrícolas: 26/06/2006, 21/11/2006, 21/06/2007 e 18/03/2008. As culturas implantadas em cada período e em cada sistema de culturas estão listadas no quadro 1. Foram avaliadas duas rotações de culturas (rotação A e rotação B) e solo mantido sob pousio no inverno,
Quadro 1. Sistemas de culturas empregados durante quatro ciclos de cultivo

\begin{tabular}{clll}
\hline \multirow{2}{*}{ Coleta } & \multicolumn{3}{c}{ Sistema de Cultura } \\
\cline { 2 - 4 } & Rotação A & Rotação B & \multicolumn{1}{c}{ Pousio } \\
\hline 1 & Trigo & Aveia+Vica & Espontâneas \\
2 & Milho & Milho & Milho \\
3 & Aveia+ Vica & Aveia+Vica & Espontâneas \\
4 & Soja & Soja & Soja \\
\hline
\end{tabular}

nos sistemas de preparo de solo convencional (PC) e plantio direto $(\mathrm{PD})$, além do campo natural $(\mathrm{CN})$, adotado como o sistema referencial, no qual não foi realizada operação para implantação de culturas anuais. Neste tratamento foi realizada simulação de pastejo por meio de operações de sega e coleta do resíduo vegetal semestralmente, além de não ter sido feita reposição de nutrientes por meio de adubações.

Os tratamentos foram dispostos em parcelas principais caracterizadas pelos sistemas de culturas (30 x $30 \mathrm{~m})$ e subparcelas para os preparos de solo (7,5 x $30 \mathrm{~m})$; para cada coleta das amostras, as parcelas foram divididas em três pontos de amostragem. Cada amostra foi constituída por 15 subamostras coletadas de forma completamente casualizada, com auxílio de um trado calador, na profundidade de $0-7 \mathrm{~cm}$, formando uma massa final de aproximadamente $500 \mathrm{~g}$ por amostra. A coleta da camada superficial do solo foi realizada a fim de priorizar a região com maior atividade microbiana do solo. $\mathrm{O}$ processamento das amostras consistiu na tamisagem do solo em peneira com malha de $2 \mathrm{~mm}$, sendo mantidas por no máximo uma semana em geladeira, para as análises de atividade e biomassa microbiana, ou secas ao ar e armazenadas por até 20 dias, para as análises de atividade enzimática. As coletas foram realizadas na fase reprodutiva das culturas, exceto na última amostragem, que foi efetuada no final do ciclo da soja - esta a espécie implantada em todos os tratamentos naquele momento. Na primeira coleta, as amostras foram enviadas para o Laboratório de Análise de Solos da Universidade Federal do Rio Grande do Sul, para que fosse feita a caracterização química do solo em cada tratamento (Quadro 2).

Quadro 2. Análise química do solo com campo natural ou manejado sob preparo convencional (PC) ou plantio direto (PD) e submetido a dois sistemas de rotação de culturas ou pousio no inverno (Quadro 1), na camada de $0-7 \mathrm{~cm}$ de profundidade

\begin{tabular}{|c|c|c|c|c|c|c|c|c|c|}
\hline Sistema & $\mathbf{P}$ & $\mathbf{K}$ & MO & $\mathbf{p H}$ & SMP & $\mathrm{Al}^{3+}$ & $\mathrm{Ca}^{2+}$ & $\mathrm{Mg}^{2+}$ & Argila \\
\hline & \multicolumn{2}{|c|}{$-\mathrm{mg} \mathrm{dm} \mathrm{m}^{-3}-$} & \multicolumn{2}{|l|}{$\%$} & & \multicolumn{2}{|c|}{$-\mathrm{cmol}_{\mathrm{c}} \mathrm{dm}^{-3}$} & - & $\%$ \\
\hline PD/Rotação A & 24,0 & 258 & 4,4 & 6,5 & 6,8 & 0,0 & 9,3 & 5,1 & 30 \\
\hline PD/Rotação B & 35,0 & 232 & 4,2 & 6,3 & 6,7 & 0,0 & 8,9 & 5,1 & $\begin{array}{l}31 \\
28\end{array}$ \\
\hline PD/Pousio & 15,0 & 219 & 3,8 & 6,7 & 6,9 & 0,0 & 7,4 & 3,7 & 28 \\
\hline PC/Rotação A & 18,0 & 235 & 2,5 & 5,7 & 6,3 & 0,0 & 4,0 & 2,6 & 32 \\
\hline PC/Rotação B & 19,0 & 237 & 2,7 & 5,7 & 6,3 & 0,0 & 4,2 & 2,6 & 33 \\
\hline $\mathrm{PC} /$ Pousio & 9,6 & 204 & 2,7 & 5,9 & 6,3 & 0,0 & 4,0 & 2,2 & 29 \\
\hline Campo Natural & 7,7 & 167 & 4,6 & 5,2 & 6,1 & 0,3 & 3,1 & 2,2 & 32 \\
\hline
\end{tabular}


Após o processamento, as amostras foram submetidas às análises de $\mathrm{C}$ da biomassa microbiana, atividade respiratória e atividade das enzimas $\beta$-glicosidase (ciclo do $\mathrm{C}$ ), fosfatase ácida (ciclo do $\mathrm{P}$ ), arilsulfatase (ciclo do S) e urease (ciclo do N). Na avaliação do $\mathrm{C}$ da biomassa microbiana foi utilizado o método da fumigação-incubação (Jenkinson \& Powlson, 1976), empregando-se o fator de correção proposto por Horwath et al. (1996). As amostras não fumigadas foram mantidas em incubação por um período de 60 dias, ao longo do qual se avaliou a atividade respiratória.

Para avaliação da atividade enzimática do solo, utilizaram-se métodos propostos por Dick et al. (1996). Empregou-se, no entanto, a adaptação proposta por Verchot \& Borelli (2005), que descartaram o uso de tolueno para inibir a atividade microbiana no processo de análise, tendo em vista que não foram identificadas diferenças entre amostras nas quais o inibidor microbiano foi utilizado e aquelas em que não houve adição deste.

Os dados obtidos nas diferentes avaliações foram analisados segundo um delineamento totalmente casualizado, com o emprego de três repetições. As médias foram avaliadas em teste de contrastes ortogonais, em nível de significância de $5 \%$, a fim de separar os efeitos de preparo do solo e sistema de culturas.

\section{RESULTADOS E DISCUSSÃO}

\section{Biomassa Microbiana}

$\mathrm{Na}$ comparação realizada com o contraste PC x CN/PD (Quadros 3 e 4), observa-se que, em todos os períodos, ocorreram diferenças significativas, sendo os maiores valores de biomassa obtidos no grupo CN/PD. Da mesma forma, na comparação entre o PC e o PD, em todas as amostragens foram

Quadro 3. Médias dos grupos avaliados nos contrastes ortogonais para valores de biomassa microbiana do solo

\begin{tabular}{lcccc}
\hline \multirow{2}{*}{ Grupo } & \multicolumn{4}{c}{ Período(1) $^{(\mathbf{c}}$} \\
\cline { 2 - 5 } & $\mathbf{1}$ & $\mathbf{2}$ & $\mathbf{3}$ & $\mathbf{4}$ \\
\hline & \multicolumn{4}{c}{$\mathrm{mg} \mathrm{kg}^{-1} \mathrm{C}$} \\
$\mathrm{CN}$ & 463,9 & 360,2 & 476,7 & 238,3 \\
$\mathrm{PD}$ & 454,4 & 322,3 & 378,9 & 195,0 \\
$\mathrm{PC}$ & 374,5 & 279,1 & 239,4 & 129,9 \\
CN/PD & 459,2 & 341,3 & 427,8 & 216,7 \\
Rotação A & 411,5 & 375,2 & 261,4 & 137,3 \\
Rotação B & 419,5 & 396,5 & 318,4 & 158,2 \\
Pousio & 412.4 & 280,5 & 347,8 & 119,9 \\
\hline
\end{tabular}

(1) $1=26 / 06 / 2006 ; 2=21 / 11 / 2006 ; 3=21 / 06 / 2007$ e $4=18 / 03 / 2008$. $\mathrm{CN}$ : campo natural, PD: plantio direto e PC: preparo convencional.
Quadro 4. Contrastes ortogonais para sistemas de preparo e de culturas, em função da biomassa microbiana do solo

\begin{tabular}{|c|c|c|c|c|}
\hline \multirow{2}{*}{ Contraste } & \multicolumn{4}{|c|}{ Período $^{(1)}$} \\
\hline & 1 & 2 & 3 & 4 \\
\hline $\mathrm{PC} \times \mathrm{CN} / \mathrm{PD}$ & $*$ & $*$ & * & $*$ \\
\hline $\mathrm{PD} \times \mathrm{PC}$ & * & $*$ & * & $*$ \\
\hline $\mathrm{CN} \times \mathrm{PD}$ & ns & $\mathrm{ns}$ & $\mathrm{ns}$ & $\mathrm{ns}$ \\
\hline Rotação A x Rotação B & ns & $\mathrm{ns}$ & $\mathrm{ns}$ & $\mathrm{ns}$ \\
\hline Rotação A x Pousio & ns & $*$ & ns & ns \\
\hline Rotação B x Pousio & $\mathrm{ns}$ & * & $\mathrm{ns}$ & $*$ \\
\hline
\end{tabular}

determinadas diferenças entre os dois sistemas de manejo, sendo a biomassa microbiana superior no PD, com exceção do segundo período de avaliação, quando foi superior no PC. De modo geral, esses resultados assemelham-se aos obtidos por Eekeren et al. (2008), que observaram valores mais elevados de biomassa em tratamento com PD, em comparação com o sistema de cultura de milho que empregava sempre a operação de aração. Conforme Roldán et al. (2003), o aumento da biomassa microbiana do solo está relacionado com a adoção do PD e com o aumento da adição de resíduos culturais na superfície do solo.

$\mathrm{Na}$ comparação entre $\mathrm{PD}$ e o $\mathrm{CN}$, não foram verificadas diferenças significativas nos quatro períodos de avaliação, indicando que o PD tende a manter a quantidade de biomassa microbiana, semelhantemente ao sistema referencial. De forma similar, Mijangos et al. (2006) observaram que os valores de biomassa microbiana no $\mathrm{PC}$ foram baixos em relação ao $\mathrm{PD}$ e ao $\mathrm{CN}$, enquanto esses dois sistemas não apresentaram diferenças entre si.

Sabe-se que as variações no $\mathrm{C}$ da biomassa microbiana e a atividade desta possuem relação direta com as variações do C orgânico no solo (Alvarez, 1995), indicando que os sistemas que contribuem para o aumento da MO, como o PD e o CN (Quadro 2), são os que proporcionam a manutenção de maior biomassa microbiana. De forma inversa, no sistema PC, em função do método de preparo, os resíduos culturais são colocados em contato mais íntimo com o solo, além de favorecer o rompimento dos agregados, expondo frações protegidas da MO. Em razão desses fatores, há estímulo temporário da microbiota logo após o revolvimento do solo, acelerando a decomposição da matéria orgânica, além do fato de o solo ser mantido descoberto, favorecendo com isso as perdas de C por erosão (Lee et al., 1993).

Quanto aos sistemas de culturas, não foram observadas diferenças na biomassa microbiana entre as rotações. Entretanto, quando comparadas as rotações com o pousio, no segundo e quarto períodos 
ocorreram diferenças, com o pousio apresentando médias inferiores às das rotações. O resultado é similar ao obtido por Carter (1986), que observou aumento na biomassa microbiana nos sistemas que utilizavam rotação de culturas em vez do pousio na produção de trigo. Contudo, no conjunto dos quatro períodos, não há nítida diferença entre o pousio e as rotações, Vargas \& Scholles (2000) também não identificaram diferenças na biomassa microbiana entre os sistemas de culturas, mesmo entre aqueles que utilizavam ou não leguminosas. Segundo Robinson et al. (1996), os efeitos positivos que podem ser obtidos pela utilização da rotação de culturas estão ligados à possibilidade de haver maior aporte de $\mathrm{C}$ ao sistema, bem como o fornecimento de diferentes tipos de resíduos vegetais ao solo. No entanto, o que vai determinar esses efeitos, em última instância, será a escolha das espécies utilizadas no sistema. A MO do solo sob pousio foi semelhante à encontrada no solo em que se implantaram as rotações, motivo pelo qual as diferenças entre os sistemas de culturas não foram observadas de forma consistente nos quatro períodos de avaliação.

\section{Atividade respiratória}

O comportamento da atividade respiratória foi similar ao verificado na avaliação da biomassa microbiana. Mediante a análise de emissão de $\mathrm{CO}_{2}$, foi possível identificar diferenças entre os sistemas de preparo do solo (Quadros 5 e 6). A comparação do sistema que envolve intensa movimentação de solo (PC) com os que promovem baixo ou nenhum revolvimento (CN/PD) revelou que as taxas respiratórias foram superiores, nos quatro períodos, no grupo $\mathrm{CN} / \mathrm{PD}$, indicando que esses manejos com características conservacionistas favoreceram mais a atividade microbiana no solo. Segundo Bradford \& Peterson (2000), sistemas agrícolas que não utilizam a movimentação de solo tendem a apresentar maior atividade microbiana, em decorrência do aporte gradual de $\mathrm{C}$, de menor amplitude térmica em razão da cobertura do solo e da manutenção da umidade na camada superficial.

Quadro 5. Médias dos grupos avaliados nos contrastes ortogonais para taxa de atividade respiratória da microbiota do solo

\begin{tabular}{|c|c|c|c|c|}
\hline \multirow{2}{*}{ Grupo } & \multicolumn{4}{|c|}{ Período ${ }^{(1)}$} \\
\hline & 1 & 2 & 3 & 4 \\
\hline & & $\mathrm{mg} \mathrm{kg} \mathrm{c}$ & C no solo & \\
\hline $\mathrm{CN}$ & 7,0 & 7,1 & 8,2 & 9,3 \\
\hline $\mathrm{PD}$ & 8,2 & 6,7 & 5,2 & 8,5 \\
\hline $\mathrm{PC}$ & 5,2 & 6,5 & 4,8 & 5,0 \\
\hline $\mathrm{CN} / \mathrm{PD}$ & 7,4 & 6,9 & 6,7 & 8,9 \\
\hline Rotação A & 6,7 & 6,8 & 4,1 & 6,7 \\
\hline Rotação B & 6,3 & 7,3 & 5,5 & 6,5 \\
\hline Pousio & 7,2 & 5,7 & 5,4 & 7,0 \\
\hline
\end{tabular}

Quadro 6. Contrastes ortogonais para sistemas de preparo e de culturas, em função da atividade respiratória da microbiota do solo

\begin{tabular}{lcccc}
\hline \multirow{2}{*}{ Contraste } & \multicolumn{4}{c}{ Período(1) $^{(1)}$} \\
\cline { 2 - 5 } & $\mathbf{1}$ & $\mathbf{2}$ & $\mathbf{3}$ & $\mathbf{4}$ \\
\hline $\mathrm{PC} \times \mathrm{CN} / \mathrm{PD}$ & $*$ & $*$ & $*$ & $*$ \\
$\mathrm{PD} \times \mathrm{PC}$ & $*$ & $*$ & $\mathrm{~ns}$ & $*$ \\
CN x PD & $\mathrm{ns}$ & $\mathrm{ns}$ & $*$ & $\mathrm{~ns}$ \\
Rotação A x Rotação B & $\mathrm{ns}$ & $\mathrm{ns}$ & $*$ & $\mathrm{~ns}$ \\
Rotação A x Pousio & $\mathrm{ns}$ & $\mathrm{ns}$ & $*$ & $\mathrm{~ns}$ \\
Rotação B x Pousio & $\mathrm{ns}$ & $\mathrm{ns}$ & $\mathrm{ns}$ & $\mathrm{ns}$ \\
\hline
\end{tabular}

(1) 1 = 26/06/2006; 2 = 21/11/2006; 3 = 21/06/2007 e $4=18 / 03 / 2008$.

* Diferença significativa a $5 \%$. ns: diferença não significativa. $\mathrm{CN}$ : campo natural, PD: plantio direto e PC: preparo convencional.

Quando o sistema referência não foi considerado e a comparação foi realizada apenas entre PD e $\mathrm{PC}$, foi verificada atividade microbiana superior no $\mathrm{PD}$, exceto no terceiro período de amostragem. Esses resultados assemelham-se aos dos trabalhos de Balota et al. (1997), Sall et al. (2006) e Meriles et al. (2009), que, avaliando sistemas de culturas com diferentes preparos de solo, constataram que a atividade respiratória foi superior nos manejos que não promoviam revolvimento de solo. Da mesma forma, Vargas \& Scholles (2000) observaram que a atividade microbiana do solo foi favorecida pelo emprego do PD. Nesse trabalho, esses autores concluem que a maior disponibilidade de $\mathrm{C}$ nas camadas superficiais do solo, proporcionada pelo $\mathrm{PD}$, favorece a atividade dos microrganismos - comportamento semelhante ao observado no presente trabalho.

Na comparação entre o PD e o sistema referência $\mathrm{CN}$, observa-se que apenas no terceiro período ocorreu diferença significativa na atividade respiratória, sendo superior no CN. Há, portanto, equivalência entre os dois sistemas no que diz respeito à atividade microbiana avaliada pela emissão de $\mathrm{CO}_{2}$. De modo semelhante, Constantini et al. (1996) observaram que a atividade microbiana em solo com milho sob PD foi similar à obtida em uma pastagem nativa preservada por 20 anos, na Argentina. Por outro lado, Mijangos et al. (2006), em pesquisa que avaliou diferentes sistemas de preparo e fertilização orgânica do solo, observaram que a atividade respiratória do solo foi superior em PD em relação ao PC, porém o maior valor de emissão de $\mathrm{CO}_{2}$ foi obtido no $\mathrm{CN}$, superando inclusive o $\mathrm{PD}$, que recebeu aporte de matéria orgânica por meio da adubação orgânica.

No que se refere aos sistemas de culturas, de maneira geral, não foi percebida tendência em termos de atividade respiratória (Quadro 6). Resultados semelhantes foram obtidos por Vargas \& Scholles (2000) e Meriles et al. (2009), que também não identificaram, de forma clara, efeitos dos sistemas de culturas sobre a emissão de $\mathrm{CO}_{2}$. 
Mesmo no primeiro período de amostragem, no qual havia diferentes coberturas vegetais nos três sistemas de culturas - isto é, trigo na rotação A, aveia + ervilhaca na rotação B e espontâneas no pousio -, não foram observadas diferenças significativas na atividade respiratória entre os tratamentos. Esse resultado contrasta com o obtido por Catelan \& Vidor (1990), que identificaram maior emissão de $\mathrm{CO}_{2}$ no tratamento cultivado com aveia + ervilhaca / milho + caupi, em relação ao tratamento com aveia / milho. Esses autores relacionam esse dado com a maior atividade rizosférica proporcionada pelo emprego de leguminosas, tanto no período de verão quanto no de inverno.

\section{Atividade enzimática}

\section{Atividade $\beta$-glicosidase}

Houve diferenças significativas de atividade da $\beta$-glicosidase entre os sistemas de preparo do solo (Quadros 7 e 8). No contraste que compara o preparo convencional com o grupo que não emprega o revolvimento do solo, observaram-se diferenças significativas nos quatro períodos de amostragem, sendo as maiores taxas de atividade dessa enzima obtidas no PD.

Quadro 7. Médias dos grupos avaliados nos contrastes ortogonais para valores de atividade da enzima $\beta$-glicosidase

\begin{tabular}{lrrrr}
\hline \multirow{2}{*}{ Grupo } & \multicolumn{4}{c}{ Período(1) $^{(1)}$} \\
\cline { 2 - 5 } & $\mathbf{1}$ & $\mathbf{2}$ & $\mathbf{3}$ & $\mathbf{4}$ \\
\hline & \multicolumn{4}{c}{ mg $\rho$-nitrofenol kg solo-1 $\mathrm{h}^{-1}$} \\
$\mathrm{CN}$ & 107,0 & 73,2 & 80,9 & 119,4 \\
$\mathrm{PD}$ & 172,3 & 107,0 & 92,4 & 119,1 \\
$\mathrm{PC}$ & 76,8 & 63,5 & 61,5 & 50,9 \\
CN/PD & 139,7 & 90,1 & 86,7 & 119,3 \\
Rotação A & 113,6 & 82,9 & 76,1 & 80,7 \\
Rotação B & 208,4 & 870 & 82,3 & 83,2 \\
Pousio & 155,8 & 86,0 & 70,2 & 69,2 \\
\hline (1) 1 = 26/06/2006; $2=21 / 11 / 2006 ; 3=21 / 06 / 2007$ e $4=18 / 03 / 2008$ \\
CN: campo natural, PD: plantio direto e PC: preparo convencional.
\end{tabular}

Quadro 8. Contrastes ortogonais para sistemas de preparo e de culturas, em função da atividade da enzima $\beta$-glicosidase

\begin{tabular}{lcccc}
\hline \multirow{2}{*}{ Contraste } & \multicolumn{4}{c}{ Período(1) $^{(1)}$} \\
\cline { 2 - 5 } & $\mathbf{1}$ & $\mathbf{2}$ & $\mathbf{3}$ & $\mathbf{4}$ \\
\hline PC x CN/PD & $*$ & $*$ & $*$ & $*$ \\
PD x PC & $*$ & $*$ & $*$ & $*$ \\
CN x PD & $*$ & $*$ & $\mathrm{~ns}$ & $\mathrm{~ns}$ \\
Rotação A x Rotação B & $\mathrm{ns}$ & $\mathrm{ns}$ & $\mathrm{ns}$ & $\mathrm{ns}$ \\
Rotação A x Pousio & $*$ & $\mathrm{~ns}$ & $\mathrm{~ns}$ & $\mathrm{Ns}$ \\
Rotação B x Pousio & $\mathrm{ns}$ & $\mathrm{ns}$ & $\mathrm{ns}$ & $\mathrm{Ns}$ \\
\hline (1) 1=26/06/2006; 2=21/11/2006; 3=21/06/2007 e 4=18/03/2008. \\
* Diferença significativa a 5 \%. ns: diferença não significativa. \\
CN: campo natural, PD: plantio direto e PC: preparo convencional.
\end{tabular}

O contraste PD x PC mostrou diferenças significativas em todos os períodos, sendo sempre a maior atividade de $\beta$-glicosidase obtida no PD. Roldán et al. (2005b) obtiveram resultados similares na comparação de preparos com e sem movimentação de solo em relação à atividade dessa enzima. Nesse trabalho, esses autores avaliaram diferentes sistemas de produção de sorgo no México, observando que a atividade da $\beta$-glicosidase foi praticamente duas vezes superior em PD em relação ao PC, na profundidade de 0 a $5 \mathrm{~cm}$. Em avaliações em maiores profundidades, eles observaram que a atividade da enzima em PD diminuía, enquanto em PC se mantinha uniforme. De forma semelhante, van den Bossche et al. (2008) verificaram que a atividade dessa enzima era cerca de duas vezes superior nos sistema PD e preparo reduzido, em comparação ao $\mathrm{PC}$. Os autores associaram o resultado à maior capacidade dos sistemas conservacionistas em aumentar o conteúdo de $\mathrm{C}$ do solo, principalmente nas camadas superficiais - conclusão corroborada por Melero et al. (2008).

Por outro lado, Roldán et al. (2003) não encontraram diferenças na atividade da enzima entre PD e PC em sistemas de cultivo de milho, quando o resíduo vegetal foi removido do PD. Quando a palha era mantida cobrindo $66 \%$ do solo, a atividade da enzima era mais de duas vezes superior à do $\mathrm{PC}$, indicando que a atividade da $\beta$-glicosidase está relacionada com o aumento da adição de resíduos vegetais e, portanto, com a ciclagem de $\mathrm{C}$ no solo. Os resultados desses autores demonstram a importância não apenas de se manter o solo sem revolvimento, mas também da produção de biomassa vegetal e de sua manutenção em cobertura no PD.

$\mathrm{Na}$ comparação entre $\mathrm{PD}$ e $\mathrm{CN}$, nas duas primeiras amostragens, a atividade da $\beta$-glicosidase foi superior no PD, enquanto nas duas seguintes não foram identificadas diferenças significativas. Esses resultados foram semelhantes aos observados na avaliação da atividade respiratória do solo, que indiretamente indica a quantidade de $\mathrm{C}$ mineralizável. O comportamento similar entre essas duas variáveis pode ser explicado pelo fato de a atividade da enzima $\beta$-glicosidase estar ligada à liberação de açúcares de baixo peso molecular a partir da decomposição da MO, os quais são importantes fontes de energia metabólica para a microbiota do solo, de acordo com Bandick \& Dick (1999). Esses autores observaram que os valores de atividade dessa enzima nos sistemas de pastagem permanente foram sempre superiores aos obtidos nos sistemas cultivados. Eles atribuíram seus resultados ao fato de não haver revolvimento de solo na pastagem e de a atividade rizosférica ser permanente neste sistema. No presente trabalho, os sistemas PC e PD recebiam fertilizantes de acordo com a recomendação oficial (CQFSRS, 2004) a cada implantação de culturas (duas vezes ao ano), enquanto o $\mathrm{CN}$, além 
de não receber fertilização, ainda era submetido a corte e remoção da vegetação (duas vezes ao ano) para simular o pastoreio. A menor disponibilidade de nutrientes pode ter contribuído para redução na atividade de $\beta$-glicosidase, nesse sistema, em dois dos quatro períodos amostrados.

Com exceção do contraste rotação A x pousio no primeiro período de avaliação, a atividade da enzima não foi alterada pelos sistemas de culturas, corroborando os resultados dos indicadores anteriores. Roldán et al. (2003) observaram que a atividade da enzima $\beta$-glicosidase decrescia com o emprego de leguminosas. Esse resultado não foi observado neste trabalho, tendo em vista que apenas na segunda amostragem não havia a presença de leguminosas. Naquele período de avaliação, havia apenas o cultivo de milho e, observando-se as médias, não foi possível perceber efeito claro do aumento da atividade da enzima na ausência de leguminosas. Provavelmente, essa relação entre o decréscimo da atividade da enzima e a presença de leguminosas não seja de fato generalizada, pois, em trabalho que avaliou o efeito de sistemas de rotação de culturas, Miller \& Dick (1995) observaram que, nos sistemas que utilizavam trevo-vermelho, a atividade da $\beta$-glicosidase foi superior à de onde não havia a utilização da leguminosa.

\section{Atividade da fosfatase ácida}

$\mathrm{Na}$ comparação entre os sistemas sem movimentação de solo com o PC (Quadros 9 e 10), observou-se que a atividade da fosfatase ácida foi significativamente superior, nas quatro avaliações, no grupo CN/PD. Da mesma forma, a atividade da fosfatase ácida no PD foi maior do que no PC. O resultado é similar ao obtido por Roldán et al. (2005a, 2007), que compararam esses sistemas de preparo nas culturas de milho e feijão. Nesse trabalho, a maior atividade da enzima foi relacionada - além do fato de que o PD tende a aumentar o estoque de $\mathrm{C}$ no solo - também à maior

Quadro 9. Médias dos grupos avaliados nos contrastes ortogonais para valores de atividade da enzima fosfatase ácida

\begin{tabular}{|c|c|c|c|c|}
\hline \multirow{2}{*}{ Grupo } & \multicolumn{4}{|c|}{ Período(1) } \\
\hline & 1 & 2 & 3 & 4 \\
\hline & \multicolumn{4}{|c|}{ mg $\rho$-nitrofenol kg solo ${ }^{-1} \mathrm{~h}^{-1}$} \\
\hline $\mathrm{CN}$ & 80,9 & 119,9 & 432,3 & 82,2 \\
\hline $\mathrm{PD}$ & 92,4 & 109,6 & 302,6 & 88,5 \\
\hline $\mathrm{PC}$ & 61,5 & 92,3 & 231,8 & 63,5 \\
\hline $\mathrm{CN} / \mathrm{PD}$ & 86,7 & 114,8 & 367,5 & 85,4 \\
\hline Rotação A & 76,1 & 108,5 & 279,0 & 74,9 \\
\hline Rotação B & 82,3 & 108,0 & 285,5 & 84,9 \\
\hline Pousio & 72,5 & 110,6 & 237,2 & 71,7 \\
\hline
\end{tabular}

(1) 1 =26/06/2006; $2=21 / 11 / 2006 ; 3=21 / 06 / 2007$ e $4=18 / 03 / 2008$. $\mathrm{CN}$ : campo natural, PD: plantio direto e PC: preparo convencional.
Quadro 10. Contrastes ortogonais para sistemas de preparo e de culturas, em função da atividade da enzima fosfatase ácida

\begin{tabular}{lcccc}
\hline \multirow{2}{*}{ Contraste } & \multicolumn{4}{c}{ Período(1) $^{(1)}$} \\
\cline { 2 - 5 } & $\mathbf{1}$ & $\mathbf{2}$ & $\mathbf{3}$ & $\mathbf{4}$ \\
\hline $\mathrm{PC} \times \mathrm{CN} / \mathrm{PD}$ & $*$ & $*$ & $*$ & $*$ \\
PD x PC & $*$ & $*$ & $*$ & $*$ \\
CN x PD & $*$ & $*$ & $*$ & $*$ \\
Rotação A x Rotação B & $*$ & $\mathrm{~ns}$ & $*$ & $\mathrm{~ns}$ \\
Rotação A x Pousio & $\mathrm{ns}$ & $\mathrm{ns}$ & $\mathrm{ns}$ & $\mathrm{ns}$ \\
Rotação B x Pousio & $*$ & $\mathrm{~ns}$ & $\mathrm{~ns}$ & $\mathrm{~ns}$
\end{tabular}

(1) 1 =26/06/2006; 2 =21/11/2006; $3=21 / 06 / 2007$ e $4=18 / 03 / 2008$.

* Diferença significativa a $5 \%$. ns: diferença não significativa. PD: plantio direto, PC: preparo convencional e CN: campo natural.

atividade de micorrizas arbusculares, as quais são favorecidas por esse sistema de preparo. Mina et al. (2008) também observaram atividade superior da enzima em solo sob PD em relação ao PC, porém as diferenças não foram tão marcantes quanto as obtidas no presente trabalho. Isso talvez possa ser explicado pela diferença da profundidade de amostragem empregada nas duas pesquisas: neste trabalho a coleta foi de $0-7 \mathrm{~cm}$, e na pesquisa citada, de $0-15 \mathrm{~cm}$. A atividade microbiana em PD tende a ser maior na superfície, em virtude da deposição de resíduo vegetal para a cobertura do solo, enquanto em PC o material é incorporado ao solo, o que dilui seu efeito (Dick, 1984).

$\mathrm{Na}$ comparação entre o $\mathrm{PD}$ e o sistema de referência $(\mathrm{CN})$, foram observadas diferenças significativas em todos os períodos de amostragem. $\mathrm{Na}$ primeira e quarta avaliações, a atividade da enzima fosfatase ácida no PD foi maior do que no $\mathrm{CN}$, ao passo que no segundo e terceiro períodos os maiores valores foram encontrados no CN. Esse resultado mostra equilíbrio entre os dois sistemas de preparo de solo, diferentemente do que foi observado em trabalho de Roldán et al. (2005b), envolvendo a cultura do sorgo com diferentes sistemas de preparo em experimento de três anos de duração. No trabalho, que partiu de áreas já degradadas no México, esses autores observaram que a atividade da fosfatase ácida no $\mathrm{CN}$ foi mais de duas vezes superior à observada no PD.

Em relação às comparações entre os sistemas de culturas, na análise da atividade da enzima fosfatase ácida foi observada diferença somente em um caso, na primeira amostragem nos contrastes rotação $A \times$ rotação $B$ e rotação $B \times$ pousio, o que indica que houve pouca influência das culturas utilizadas. O emprego de diferentes sistemas de culturas apresenta resultados controversos na literatura. Izquierdo et al. (2003), em experimento com duração de oito anos, avaliaram diferentes indicadores bioquímicos de qualidade do solo, entre eles a 
atividade de fosfatase ácida, comparando sistemas como pastagem com gramíneas tropicais, forrageiras herbáceas e rotação de culturas (mandioca/feijão/ tomate/espinafre). Esses autores observaram que os menores valores de atividade da fosfatase, assim como dos outros indicadores, ocorreram nas áreas sob rotação. Por sua vez, Deng \& Tabatabai (1997) verificaram que a atividade da fosfatase ácida foi alterada pela profundidade da amostragem e pelo tipo de preparo, mas não pelo sistema de culturas.

\section{Atividade da arilsulfatase}

Entre os sistemas de preparo, em todos os períodos de amostragem, foram encontradas diferenças significativas para a atividade da arilsulfatase (Quadros 11 e 12). No contraste PC x CN/PD, o grupo que representa os tratamentos em que não há revolvimento mostrou sempre as maiores taxas de atividade da enzima. Da mesma forma, no contraste PC x PD, houve diferenças significativas nos quatro períodos, com elevadas diferenças entre as médias. Esse resultado corrobora os obtidos por Melero et al. (2008) em estudo que comparou PC e $\mathrm{PD}$ em sistemas de produção de grãos na Espanha. Esses autores observaram que a atividade da enzima arilsulfatase no $\mathrm{PD}$ foi superior à obtida no $\mathrm{PC}$ e

Quadro 11. Médias dos grupos avaliados nos contrastes ortogonais para valores de atividade da enzima arilsulfatase

\begin{tabular}{|c|c|c|c|c|}
\hline \multirow{2}{*}{ Grupo } & \multicolumn{4}{|c|}{ Período(1) } \\
\hline & 1 & 2 & 3 & 4 \\
\hline & \multicolumn{4}{|c|}{$\operatorname{mg} \rho$-nitrofenol kg solo ${ }^{-1} \mathrm{~h}^{-1}$} \\
\hline $\mathrm{CN}$ & 440,3 & 58,3 & 154,8 & 217,7 \\
\hline $\mathrm{PD}$ & 228,6 & 74,2 & 116,8 & 113,3 \\
\hline $\mathrm{PC}$ & 90,8 & 14,5 & 63,6 & 65,4 \\
\hline $\mathrm{CN} / \mathrm{PD}$ & 334,5 & 66,3 & 135,8 & 165,5 \\
\hline Rotação A & 161,3 & 81,5 & 132,5 & 105,8 \\
\hline Rotação B & 144,2 & 64,3 & 120,3 & 115,5 \\
\hline Pousio & 173,6 & 79,9 & 97,7 & 118,4 \\
\hline
\end{tabular}

Quadro 12. Contrastes ortogonais para sistemas de preparo e de culturas, em função da atividade da enzima arilsulfatase

\begin{tabular}{lcccc}
\hline \multirow{2}{*}{ Contraste } & \multicolumn{4}{c}{ Período(1) $^{(1)}$} \\
\cline { 2 - 5 } & $\mathbf{1}$ & $\mathbf{2}$ & $\mathbf{3}$ & $\mathbf{4}$ \\
\hline PC x CN/PD & $*$ & $*$ & $*$ & $*$ \\
PD x PC & $*$ & $*$ & $*$ & $*$ \\
CN x PD & $*$ & $*$ & $*$ & $*$ \\
Rotação A x Rotação B & $\mathrm{ns}$ & $*$ & $\mathrm{~ns}$ & $*$ \\
Rotação A x Pousio & $\mathrm{ns}$ & $\mathrm{ns}$ & $\mathrm{ns}$ & $*$ \\
Rotação B x Pousio & $*$ & $\mathrm{~ns}$ & $\mathrm{~ns}$ & $\mathrm{~ns}$ \\
\hline (1) 1=26/06/2006; 2= 21/11/2006; 3 = 21/06/2007 e 4= 18/03/2008. \\
* Diferença significativa a 5 \%. ns: diferença não significativa. \\
CN: campo natural, PD: plantio direto e PC: preparo convencional.
\end{tabular}

relacionaram esse fato ao aumento do estoque do $\mathrm{C}$ no solo com o preparo menos intensivo.

Quando o PD foi comparado com o sistema referencial, em relação à atividade da arilsulfatase, observaram-se diferenças significativas nas quatro avaliações. Com exceção do segundo período, os maiores valores de atividade dessa enzima ocorreram no CN. Esse resultado é semelhante ao obtido por Haynes (1999), que constatou maior atividade da arilsulfatase no $\mathrm{CN}$ em relação aos sistemas com e sem revolvimento de solo. Segundo esse autor, o resultado é explicado pelo fato de que o solo sob pastagem, diferentemente do PD e $\mathrm{PC}$, possui aporte constante de MO durante o ano, constituído por material vegetal senescente na parte tanto aérea quanto radicular, além da exsudação ininterrupta de compostos orgânicos pelas diferentes espécies vegetais. Nesse trabalho, foi observada alta correlação entre a atividade da arilsulfatase e o estoque de $\mathrm{C}$ no solo.

A atividade da arilsulfatase pode ser usada como indicadora indireta da presença de fungos no solo, uma vez que, entre os componentes da biomassa microbiana, somente os fungos possuem ésteres de sulfatos, os quais são substratos para a atividade dessa enzima (Bandick \& Dick, 1999). Conforme Calderón et al. (2001), os sistemas de preparo que utilizam menor revolvimento do solo são os que mais favorecem o aumento da população de fungos. É provável que, além das características que desfavorecem o acúmulo de $\mathrm{MO}$ no solo no PC, as operações de aração e gradagem também tenham influenciado de maneira negativa as populações de fungos e, consequentemente, a atividade da arilsulfatase.

No que se refere aos sistemas de culturas, a atividade da enzima arilsulfatase não apresentou diferenças significativas apenas na terceira amostragem. Contudo, não foi observado comportamento que representasse uma tendência estável ao longo do tempo, o que é evidenciado na segunda e quarta épocas de amostragem - períodos nos quais ocorreu efeito na atividade da enzima no contraste rotação A x rotação $\mathrm{B}$. Os resultados observados naquelas duas épocas de amostragem foram opostos, com maior atividade de arilsulfatase na rotação A na segunda amostragem e maior atividade na rotação B na quarta amostragem. De forma semelhante, o solo sob pousio apresentou atividade de arilsulfatase superior à da rotação $\mathrm{B}$ na primeira amostragem e superior à da rotação $\mathrm{A}$ na quarta, não diferindo nas demais épocas, reforçando a ideia de que não houve efeito claro dos sistemas de cultura sobre a atividade da enzima.

\section{Atividade da urease}

A atividade da enzima urease diferiu significativamente no contraste $\mathrm{PC} \times \mathrm{CN} / \mathrm{PD}$, nos 
quatro períodos de avaliação (Quadros 13 e 14); a atividade da enzima foi sempre superior no grupo CN/PD. Na comparação realizada apenas entre os sistemas PC e PD, em todas as amostragens, foi constatado que a atividade da urease foi superior no PD. Esses resultados assemelham-se aos obtidos por vand den Bosshe et al. (2008), em trabalho que avaliou os impactos gerados por diferentes sistemas de preparo em diferentes solos. Nesse trabalho, os autores observaram que a atividade da urease foi sempre superior no PD em relação ao PC, nos três locais estudados. O resultado foi atribuído aos maiores teores de $\mathrm{MO}$ em $\mathrm{PD}$, o que estimularia a atividade microbiana do solo.

Quando a comparação foi realizada entre o CN e o PD, foi observado que, nos dois primeiros períodos de amostragem, a atividade da urease foi superior no PD. Contudo, no terceiro período de avaliação o resultado inverteu-se, ocorrendo maior atividade enzimática no sistema de referência, ao passo que na última determinação não foi observada diferença entre os dois sistemas. Esse resultado demonstra, de forma geral, que os solos estudados, sob preparo PD, apresentam similaridade com os solos sob

Quadro 13. Médias dos grupos avaliados nos contrastes ortogonais para valores de atividade da enzima urease

\begin{tabular}{|c|c|c|c|c|}
\hline \multirow{2}{*}{ Grupo } & \multicolumn{4}{|c|}{ Período ${ }^{(1)}$} \\
\hline & 1 & 2 & 3 & 4 \\
\hline & \multicolumn{4}{|c|}{$\mathrm{mg} \mathrm{N}-\mathrm{NH}_{4} \mathrm{~kg}$ solo $^{-1} \mathrm{~h}^{-1}$} \\
\hline $\mathrm{CN}$ & 42,7 & 32,4 & 38,4 & 39,4 \\
\hline PD & 67,2 & 43,3 & 32,5 & 38,8 \\
\hline $\mathrm{PC}$ & 17,5 & 32,5 & 24,8 & 27,8 \\
\hline $\mathrm{CN} / \mathrm{PD}$ & 55,0 & 37,9 & 35,5 & 39,1 \\
\hline Rotação A & 42,6 & 37,2 & 35,1 & 26,9 \\
\hline Rotação B & 40,0 & 38,9 & 24,9 & 29,4 \\
\hline Pousio & 44,6 & 37,6 & 26,1 & 31,2 \\
\hline
\end{tabular}

Quadro 14. Contrastes ortogonais para sistemas de preparo e de culturas, em função da atividade da enzima urease

\begin{tabular}{lcccc}
\hline \multirow{2}{*}{ Contraste } & \multicolumn{4}{c}{ Período(1) $^{(1)}$} \\
\cline { 2 - 5 } & $\mathbf{1}$ & $\mathbf{2}$ & $\mathbf{3}$ & $\mathbf{4}$ \\
\hline PC x CN/PD & $*$ & $*$ & $*$ & $*$ \\
PD x PC & $*$ & $*$ & $*$ & $*$ \\
CN x PD & $*$ & $*$ & $*$ & $\mathrm{~ns}$ \\
Rotação A x Rotação B & $\mathrm{ns}$ & $\mathrm{ns}$ & $*$ & $\mathrm{~ns}$ \\
Rotação A x Pousio & $\mathrm{ns}$ & $\mathrm{ns}$ & $*$ & $*$ \\
Rotação B x Pousio & $\mathrm{ns}$ & $\mathrm{ns}$ & $\mathrm{ns}$ & $\mathrm{ns}$ \\
\hline (1) 1=26/06/2006; 2=21/11/2006; 3=21/06/2007 e 4=18/03/2008. \\
* Diferença significativa a 5 \%. ns: diferença não significativa. \\
PD: plantio direto, PC: preparo convencional, e CN: campo \\
natural.
\end{tabular}

campo natural em termos de atividade de uma das enzimas ligadas ao ciclo do N. Esses resultados são corroborados por trabalho de Roldán et al. (2005b), no qual compararam-se preparos de solo com um sistema natural. Esses autores observaram que a atividade da enzima urease na profundidade de 0 a $5 \mathrm{~cm}$ no $\mathrm{CN}$ foi superior à do $\mathrm{PC}$, porém não diferiu significativamente do PD.

Em relação aos sistemas de culturas, foram observadas diferenças na terceira e quarta épocas de amostragem, no contraste rotação $\mathrm{A} x$ pousio. Entretanto, como demonstram as médias, não houve tendência de aumento de atividade da enzima promovida por um ou por outro sistema. Ainda no terceiro período, houve diferença no contraste entre as duas rotações, porém de forma isolada. Assim como nos demais atributos avaliados no presente trabalho, os sistemas de culturas testados não promoveram alterações evidentes na atividade da enzima urease. De modo semelhante, Conti et al. (1998), avaliando o efeito das rotações milho-soja em relação à milho-milho em $\mathrm{PD}$ na Argentina, constataram que a atividade da urease - nesses dois casos - não diferiu.

\section{CONCLUSÕES}

1. O sistema de preparo que utiliza baixa movimentação de solo (PD) assemelhou-se ao referencial $(\mathrm{CN})$, mantendo a mesma qualidade do solo da área de referência.

2. Os sistemas de culturas utilizados não promoveram impactos significativos sobre os indicadores microbianos analisados.

\section{LITERATURA CITADA}

ALBUQUERQUE, J.A.; REINERT, D.J.; FIORIN, J.E.; RUEDELL, J.; PETRERE, C. \& FONTINELLI, F. Rotação de culturas e sistemas de manejo do solo: Efeito sobre a forma da estrutura do solo ao final de sete anos. R. Bras. Ci. Solo, 19:115-119, 1995.

ALVAREZ, R. Soil organic carbon, microbial biomass and $\mathrm{CO}_{2}$ $\mathrm{C}$ production from tree tillage systems. Soil Tillage Res., $31: 17-28,1995$

BANDICK, A.K. \& DICK, R.P. Field management effects on soil enzyme activities. Soil Biol. Biochem., 31:1471-1479, 1999.

BALOTA, E.L.; COLOZZI-FILHO, A.; ANDRADE, D.S. \& HUNGRIA, M. Biomassa microbiana e sua atividade em solos sob diferentes sistemas de preparo e sucessão de culturas. R. Bras. Ci. Solo, 22:641-649, 1997.

BALOTA, E.L.; COLOZZI FILHO, A.; ANDRADE, D.S. \& DICK, R.P. Long-term tillage and crop rotation effects on microbial biomass and $\mathrm{C}$ and $\mathrm{N}$ mineralization in a Brazilian Oxisol. Soil Tillage Res., 77:137-145, 2004. 
BAYER, C. \& MIELNICZUK, J. Características químicas do solo afetadas por métodos de preparo e sistemas de cultura. R. Bras. Ci. Solo, 21:235-239, 1997.

BRADFORD, J.M. \& PETERSON, G.A. Conservation tillage. In: SUMNER, M.E., ed. Handbook of soil science. Boca Raton, CRC Press, 2000. p.247-266.

CALDERÓN, F.J.; JACKSON, L.E.; SCOW, K.M. \& ROLSTON, D.E. Short-term changes in carbon and nitrogen dynamics, microbial activity, and microbial community structure after tillage. Soil Sci. Soc. Am., 65:118-126, 2001.

CARTER, M.R. Microbial biomass as index for tillage-induced changes in soil biological properties. Soil Tillage Res., 7:29-40, 1986.

CATTELAN, A.J. \& VIDOR, C. Flutuações na biomassa, atividade e população microbiana do solo em função de variações ambientais. R. Bras. Ci. Solo, 14:133-142, 1990.

COLLARES, G.L.; REINERT, D.J.; REICHERT, J.M. \& KAISER, D.R. Qualidade física do solo na produtividade da cultura do feijoeiro num Argissolo. Pesq. Agropec. Bras., 41:16631674, 2006.

COMISSÃO DE QUÍMICA E FERTILIDADE DO SOLO CQFSRS/SC. Manual de adubação e calagem para os Estados do Rio Grande do Sul e Santa Catarina. Porto Alegre, Sociedade Brasileira de Ciência do Solo/Núcleo Regional Sul, 2004. 400p.

CONTI, M.E.; PALMA, R.M.; ARRIGO, N.M.; ZOURARAKIS, D.P. \& CAPPELLETTI, C.A. Long-term rotation effect of soybean with no-till maize on soil $\mathrm{N}$ availability inidices and microbial activity in the Argentine Pampa. Soil Tillage Res., 49:267-270, 1998.

COSTANTINI, A.; COSENTINO, I. \& SEGAT, A. Influence of tillage systems on biological properties of a Typic Argiudoll soil under continuous maize in central Argentina. Soil Tillage Res., 38:265-271, 1996.

DENG, S.P. \& TABATABAI, M.A. Effect of tillage and residue management on enzyme activities in soils: III. Phosphatases and arylsulphatase. Biol. Fert. Soils, 24:141-146, 1997.

DICK, R.P. Influence of long-term tillage and crop rotation combinations on soil enzyme activities. Soil Sci. Soc. Am., 48:569-574, 1984.

DICK, R.P.; BREACKWELL, D.P. \& TURCO, R.F. Soil enzyme activities and biodiversity measurements as integrative microbiological indicators. In: DORAN, J.W. \& JONES, A.J., eds. Methods for assessing soil quality. Madison, SSSA, 1996. p.247-271. (SSSA Special Publication, 49)

DORAN, J.W. \& JONES, A.J. Methods for assessing soil quality. Madison, SSSA, 1996. 411p. (SSSA Special Publication, 49)

EEKEREN, N.V.; BOMMELE, L.; BLOEM, J.; SCHOUTEN, T.; RUTGERS, M.; DE GOEDE, R.; REHEUL, D. \& BRUSSAARD, L. Soil biological quality after 36 years of ley-arable cropping, permanent grassland and permanent arable cropping. Appl. Soil Ecol., 40:432-446, 2008.

EMPRESA BRASILEIRA DE PESQUISA AGROPECUÁRIA EMBRAPA. Sistema brasileiro de classificação de solos. Brasília: 2006. 306p.
GIL-SOTRES, F.; CEPEDA-TRASAR, C.; LEIRÓS, M.C. \& SEOANE, S. Different approaches to evaluating soil quality using biochemical properties. Soil Biol. Biochem., 37:877-887, 2005.

GOVAERTS, B.; MEZZALAMA, M.; UNNO, Y.; SAYRE, K.D.; GUIDO, M.L.; VANHERCK, K.; DENDOOVEN, L. \& DECKERS, J. Influence of tillage, residue management, and crop rotation on soil microbial biomass and catabolic diversity. App. Soil Ecol., 37:18-30, 2007.

HAYNES, R.J. Size and activity of the soil microbial biomass under grass and arable management. Biol. Fert. Soils., 30:210-216, 1999.

HORWATH, W.R.; PAUL, E.A.; HARRIS, D.; NORTON, J.; JAGGER, L. \& HORTON, K.A. Defining a realistic control for the chloroform fumigation-incubation method using microscopic counting and ${ }^{14} \mathrm{C}$-substrates. Can. J. Soil Sci., 76:459-467,1996.

IZQUIERDO, I.; CARAVACA, F.; ALGUACIL, M.M. \& ROLDÁN, A. Changes in physical and biological soil quality indicators in a tropical crop system (Havana, Cuba) in response to different agroecological management practices. Environ. Manag., 32:639-645, 2003.

JENKINSON, D.S. \& POWLSON, D.S. The effects of biocidal treatments on metabolism in soil - V. A metod for measuring soil biomass. Soil Biol. Biochem., 8:209-213, 1976.

LEE, J.J.; PHILLIPS, D.L. \& LIU, R. The effect of trends in tillage practices on erosion and carbon content of soils in the US corn belt. Water Air Soil Poll., 70:389-401, 1993.

MELERO, S.; VANDERLINDENA, K.; RUIZA, J.C. \& MADEJONB, E. Long-term effect on soil biochemical status of a Vertisol under conservation tillage system in semi-arid Mediterranean conditions. Europ. J. Soil Biol., 44:437-442, 2008.

MERILES, J.M.; GIL, S.V.; CONFORTO, C.; FIGONI, G.; LOVERA, E.; MARCH, G.J. \& GUZMÁN, C.A. Soil Microbial communities under different soybean cropping systems: Characterization of microbial populations dynamics, soil microbial activity, microbial biomass, and fatty acids profiles. Soil Tillage Res., 103:271-281, 2009.

MIELNICZUK, J. Matéria orgânica e a sustentabilidade de sistemas agrícolas. In: SANTOS, G.A. \& CAMARGO, F.A.O., eds. Fundamentos da matéria orgânica dos solos. Porto Alegre, Gênesis, 1999. p.1-9.

MIJANGOS, I.; PÉREZ, R.; ALBIZU, I. \& GARBISU, C. Effects of fertilization and tillage on soil biological parameters. Enzimol. Microbiol. Technol., 40:100-106, 2006.

MILLER, M. \& DICK, R.P. Thermal stability and activities of soil enzymes as influenced by crop rotations. Soil Biol. Biochem., 27:1161-1166, 1995.

MINA, B.L.; SASHA, S.; KUMAR, N.; SRIVASTVA \& GUPTA, H.S. Changes in soil nutrient content and enzymatic activity under conventional and zero-tillage pratices in a Indian sandy clay loam soil. Nutr. Cycl. Agroecosyst., 88:273-281, 2008. 
POLSON, D.S. \& BROOKES, P.C. Measurement of soil microbial biomass provides an early indication of changes in total soil organic mater due to straw incorporation. Soil Biol. Biochem., 19:159-164, 1987.

REEVES, D.W. The role of soil organic matter in maintaining soil quality in continuous cropping systems. Soil Tillage Res, 43:131-167, 1997.

ROBINSON, C.A.; CRUSE, R.M. \& GHAFFARZADEH, M. Cropping systems and nitrogen effects on Mollisol organic carbon. Soil Sci. Soc. Am., 60:264-269, 1996.

ROLDÁN, A.; CARAVACA, F.; HERNÁNDEZ, M.T.; GARCÍA, C.; SÁNCHEZ-BRITO, C. VELÁSQUEZ, M. \& TISCAREÑO, M. No-tillage, crop residue additions, and legume cover cropping effects on soil quality characteristics under maize in Patzcuaro watershed (Mexico). Soil Tillage Res., 72:65-73, 2003.

ROLDÁN, A.; SALINAS-GARCÍA, J.R.; ALGUACIL, M.M. \& CARAVACA, F. Changes in soil enzyme activity, fertility, aggregation and $\mathrm{C}$ sequestration mediated by conservation tillage practices and water regime in a maize field. App. Soil Ecol., 30:11-20, 2005a.

ROLDÁN, A.; SALINAS-GARCIA, J.R.; ALGUACIL, M.M.; DÍAZ, E. \& CARAVACA, F. Soil enzyme activities suggest advantages of conservation tillages practices in sorghum cultivation under subtropical conditions. Geoderma, 129:178-185, 2005b.
ROLDÁN, A.; SALINAS-GARCÍA, J.R.; ALGUACIL, M.M. \& CARAVACA, F. Soil sustainability indicators following conservation tillage practices under subtropical maize and bean crops. Soil Tillage Res., 93:273-282, 2007.

SALL, N.S.; MASSE, D.; NDOUR, N.Y.B. \& CHOTTE, J. Does cropping modify the decomposition function and the diversity of the soil microbial community of tropical fallow soil? Appl. Soil Ecol., 31:211-219, 2006.

van den BOSSCHE, A.; DE BOLLE, S.; DE NEVE, S. \& HOFMAN, G. Effect of tillage intensity on $\mathrm{N}$ mineralization of different crop residues in a temperate climate. Soil Tillage Res., 103:316-324, 2008.

VARGAS, L.K. \& SHOLLES, D. Biomassa microbiana e produção de C-CO2 e N mineral de um Podzólico Vermelho-Escuro submetido a diferentes sistemas de manejo. R. Bras. Ci. Solo., 24:35-42, 2000.

VERCHOT, L.V. \& BORELLI, T. Application of para-nitrophenol (pNP) enzyme assays in degraded tropical soils. Soil Biol. Biochem., 37:625-633, 2005. 
